\title{
LQG Controller Design for an Industrial Boiler Turbine
}

\author{
S. K. Sunori ${ }^{1}$ \\ Graphic Era Hill University, Bhimtal, India \\ P. K. Juneja ${ }^{2}$, M. Chaturvedi ${ }^{3} \&$ M. Chauhan ${ }^{4}$ \\ Graphic Era University, Dehradun, India
}

ABSTRACT: In the present work, a boiler turbine industrial process with two manipulated variables, two controlled variables and some dead time has been considered as a case study. In order to eliminate loop interactions its decoupling is done to two separate SISO systems. Finally, an LQG controller has been designed for it and its performance is compared with that of conventional PID controllers based on Ziegler Nichol's tuning and internal model control (IMC) techniques.

\section{INTRODUCTION}

In boiler turbines, the chemical and thermal energy is transformed to electricity. It is a highly complex, multivariable, time delayed and nonlinear process $[3$, $4,5]$. In a typical boiler turbine plant a header collects all the steam which is generated from number of boilers which is then distributed to several turbines through header. The steam flow is directly proportional to power generation which is the key parameter to be controlled. The other parameter to be controlled is the drum pressure .The ultimate objective is to meet the load demand of electric power. The schematic diagram of a boiler turbine plant is depicted in figure 1 .

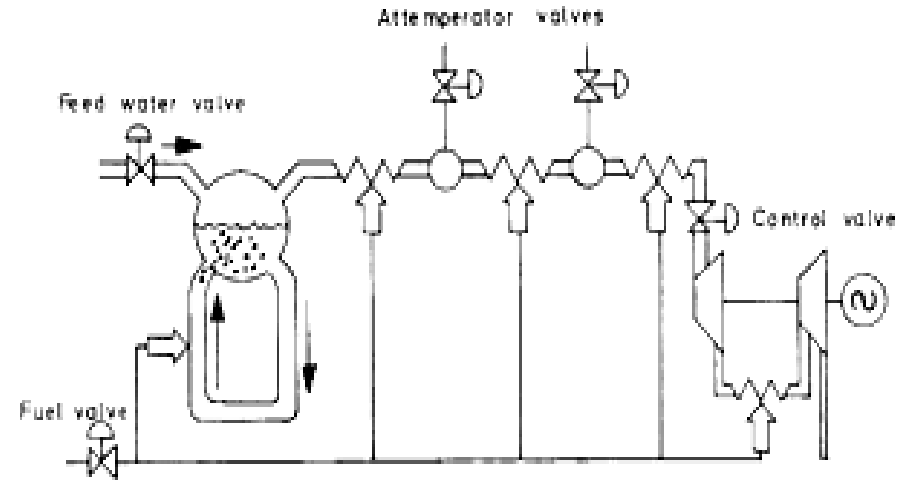

Figure 1. Schematic diagram of the boiler-turbine unit [1]

The process has two manipulated variables, the governor valve position (GV) and the fuel flow rate (FR).The variables to be controlled are the electric power (EP) and the steam pressure (SP). Equation (1) shows the considered model of an industrial boiler turbine process [2].

$$
\left[\begin{array}{l}
\mathrm{EP} \\
\mathrm{SP}
\end{array}\right]=\left[\begin{array}{cc}
\frac{68.81 e^{-2 s}}{984 s^{2}+94 s+1} & \frac{(-23.58 s-2.196) e^{-8 s}}{372 s^{2}+127 s+1} \\
\frac{e^{-2 s}}{6889 s^{2}+166 s+1} & \frac{2.194 e^{-8 s}}{6400 s^{2}+160 s+1}
\end{array}\right]\left[\begin{array}{l}
G V \\
F R
\end{array}\right]
$$

\section{PID CONTROLLER}

An industrial PID controller has many extensions over the years that make it a more practical tool for operating a chemical process. Many PID controller tuning methods have been proposed in the literature e.g. Ziegler-Nichols (ZN) tuning, Cohen-Coon tuning, direct synthesis method, internal model control (IMC) etc. In the present work ZN and IMC tuning techniques will be employed. In general, the output of a PID controller is given by equation (2).

$$
u(t)=K_{p} e(t)+K_{i} \int_{0}^{t} e(\tau) d \tau+K_{d} \frac{d e(t)}{d t}
$$

Or

$$
u(t)=K_{p}\left[e(t)+\frac{1}{T_{i}} \int_{0}^{t} e(\tau) d \tau+T_{d} \frac{d e(t)}{d t}\right]
$$

Where $\mathrm{K}_{\mathrm{p}}, \mathrm{K}_{\mathrm{i}}, \mathrm{K}_{\mathrm{d}}$ are proportional gain, integral gain and derivative gain respectively.

$\mathrm{T}_{\mathrm{i}}, \mathrm{T}_{\mathrm{d}}$ are integral and derivative time constants respectively.

\subsection{Ziegler-Nichols (ZN) Tuning}

In this method, first of all, $\mathrm{Ti}$ and $\mathrm{Td}$ are set at values $\infty$ and 0 respectively. Then the proportional gain $\mathrm{K}$ is increased from zero to a value at which sustained oscillations are set up at the output. Let this 
value of gain be Pcr and the corresponding time period be Tcr. Now, the controller tuning is done using the formulas presented in table I.

Table I Ziegler-Nichols tuning rules [6]

\begin{tabular}{|c|c|c|c|}
\hline Controller & $\mathrm{Kp}$ & $\mathrm{Ti}$ & $\mathrm{Td}$ \\
\hline $\mathrm{P}$ & $0.5 \mathrm{P}_{\mathrm{cr}}$ & $\infty$ & 0 \\
\hline $\mathrm{PI}$ & $0.45 \mathrm{P}_{\mathrm{cr}}$ & $(1 / 1.2) \mathrm{T}_{\mathrm{cr}}$ & 0 \\
\hline $\mathrm{PID}$ & $0.6 \mathrm{P}_{\mathrm{cr}}$ & $0.5 \mathrm{~T}_{\mathrm{cr}}$ & $0.125 \mathrm{~T}_{\mathrm{cr}}$ \\
\hline
\end{tabular}

\subsection{Internal Model Control (IMC) Tuning}

Any industrial process control can be successfully achieved by IMC based PID controller as it is highly robust and gives an excellent performance in case of processes with large dead time [7]. An IMC tuning rules table has been developed providing a significant disturbance rejection irrespective of the position at which the disturbance enters [8].

An IMC technique has been proposed providing an excellent rejection of the load disturbance in the situation when the desired closed loop dynamics is faster than the process dynamics. Previously done work could not do well in this situation [9].

Figures 2 and 3 are depicting the block diagrams of tuned PID controller and the designed IMC controller respectively.

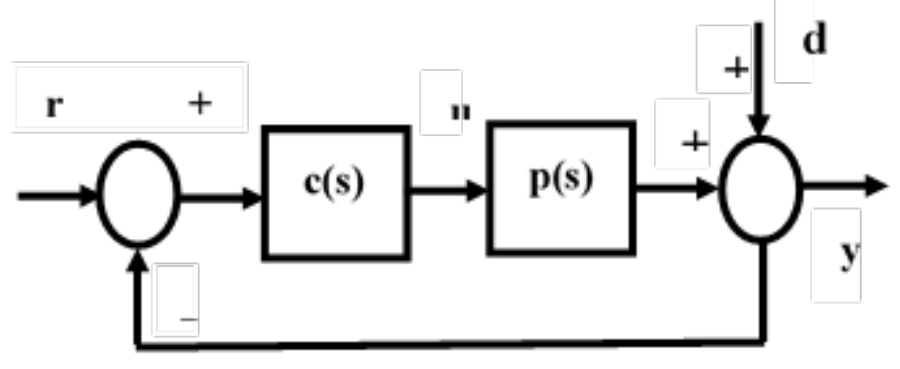

Figure 2. Block diagram of tuned PID controller

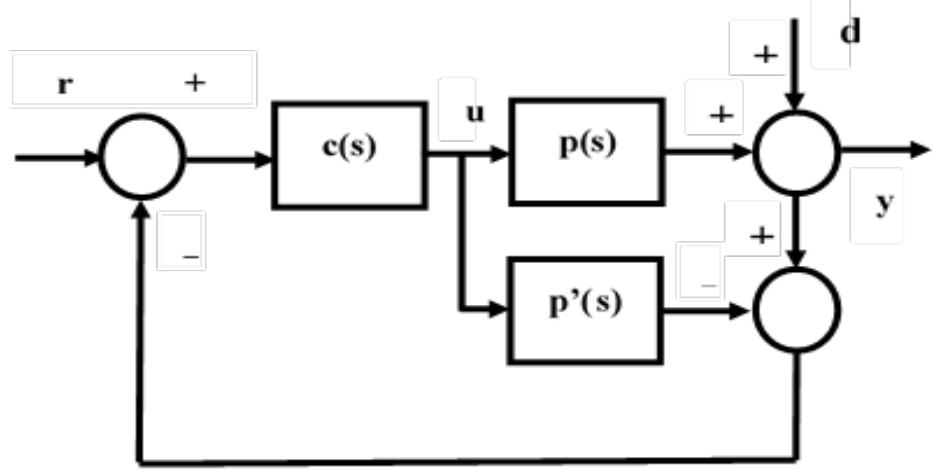

Figure 3. Block diagram of IMC controller [10]

Where,

$$
q(s)=\frac{c(s)}{1+p^{\prime}(s) c(s)}
$$

It consists of an internal model p'(s) and IMC controller $q(\mathrm{~s})$. For the perfect internal model $\mathrm{p}^{\prime}(\mathrm{s})=$ $\mathrm{p}(\mathrm{s})$. The internal stability of the IMC controller is guaranteed only if both $\mathrm{p}(\mathrm{s})$ and $\mathrm{q}(\mathrm{s})$ are stable.

\section{LQG CONTROLLER}

Consider, the state space representation of the plant to be controlled, given as,

$\dot{x}=A x+B u$

$y=C x$

The block diagram of LQR (linear quadratic regulator) for this plant is shown in figure 4 .

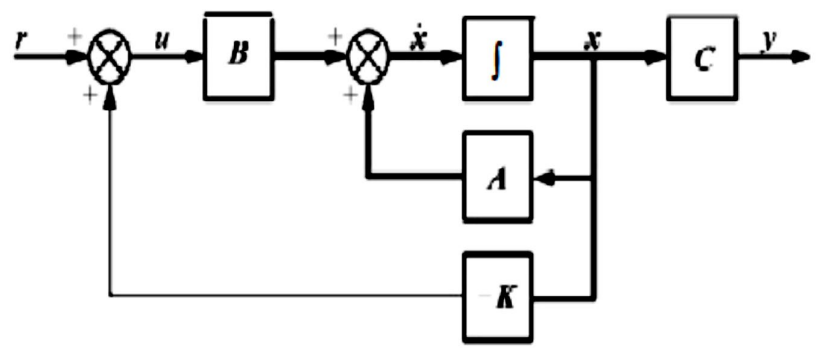

Figure 4. Block diagram of LQR [11]

This regulator minimizes the following objective function,

$$
J=\int_{0}^{\infty}\left[x^{T}(t) Q x(t)+u^{T}(t) R u(t)\right] d t
$$

Where, $\mathrm{Q}$ and $\mathrm{R}$, are weighting parameters that penalize the states and the control effort respectively. Therefore $\mathrm{Q}$ and $\mathrm{R}$ represent controller tuning parameters.

$$
u(t)=-K x(t)
$$

$\mathrm{K}$ is the gain given as,

$$
K=R^{-1} B^{T} S
$$

Where, $\mathrm{S}$ is given by the solution of the following equation called Ricatti equation,

$$
S A+A^{T} S+Q-P B R^{-1} B^{T} S=0
$$

Now, if the measurement noise $\mathrm{w}$ and the process noise v(assumed to be white Gaussian noise) are also present as shown in the state space representation of the plant in equation (10) then LQR based controller cannot perform well , as in this case the entire state vector is not available for control at all times. In this case LQG controller is designed. 
$\dot{x}=A x+B u+w$

$y=C x+v$

The simplified and detailed block diagrams of LQG controller are depicted in figures 5 and 6 respectively showing that the LQG controller combines the LQR with the Kalman filter. The Kalman filter estimates the entire state vector which is required for generation of the optimal control signal $\mathrm{u}$. The estimated error covariance is minimized by this filter.

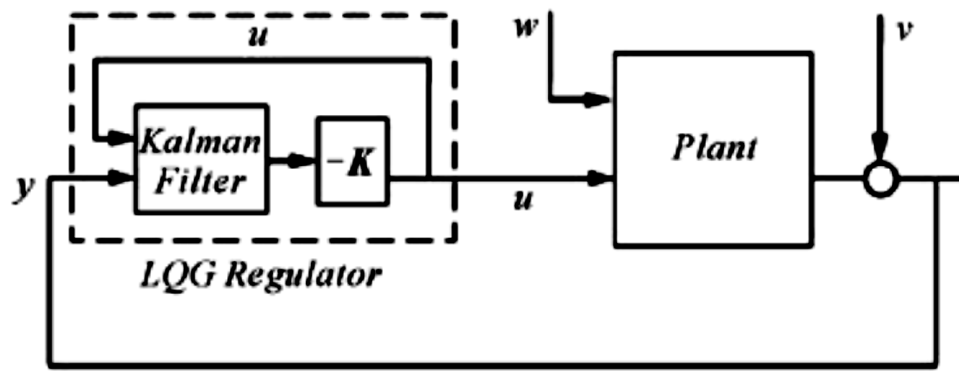

Figure 5. Simplified block diagram of LQG controller [11]



Figure 6. Detailed block diagram of LQG controller [11]

From this figure, we have,

$$
\begin{gathered}
\dot{x}=(A-L C-B K) \dot{x}+L y \\
u=-K \dot{x}
\end{gathered}
$$

Here, $\dot{x}$ represents the estimator for the state $\mathrm{x}$ and $\mathrm{L}$ is called the Kalman gain which is to be determined by the minimization of objective function (13) subject to constraint (14)

$$
\begin{gathered}
J=E\left[(x-\dot{x})^{T}(x-\dot{x})\right. \\
E\left[(x-\dot{x})^{T} y=0\right.
\end{gathered}
$$

This gives the following Kalman gain

$$
L=S_{e} C^{T} R^{-1}
$$

Where, $S_{e}$ is given by the solution of the following equation (16)

$$
S_{e} A^{T}+A S_{e}+Q-S_{e} C^{T} R^{-1} C S_{e}=0
$$

Where,

$$
Q=E\left(w w^{T}\right), R=E\left(v v^{T}\right)
$$

\section{SIMULATION WORK}

Let $\mathrm{G}(\mathrm{s})$ be the transfer matrix of a $2 \times 2$ MIMO system.

$$
[G(s)]=\left[\begin{array}{ll}
g_{11}(s) & g_{12}(s) \\
g_{21}(s) & g_{22}(s)
\end{array}\right]
$$

Then the two respective decoupled SISO systems are given by equations (18) and (19) [3]

$$
\begin{gathered}
y_{1(s)}=\left[g_{11}(s)-\frac{g_{12}(s) g_{21}(s)}{g_{22}(s)}\right] v_{1}(s) \\
y_{2(s)}=\left[g_{22}(s)-\frac{g_{12}(s) g_{21}(s)}{g_{11}(s)}\right] v_{2}(s)
\end{gathered}
$$

Using (17) and (18) we get two independent decoupled SISO systems, G1(s), which represents governor valve-Electric power system (SISO1) and G2(s), which represents Fuel flow rate-Steam pressure system (SISO2). The expressions for G1(s) and G2(s) are given in equations (20) and (21).

Now based on Pade' approximation, controllers are designed here for both decoupled SISO systems using three different techniques namely Ziegler Nichol's (ZN) tuning, internal modal control (IMC) and linear quadratic Gaussian (LQG) technique. The transfer functions of the designed ZN, IMC and LQG controllers for SISO 1 are presented as equations (22), (23) and (24) respectively.

The transfer functions of the designed ZN, IMC and LQG controllers for SISO 2 are presented as equations (25), (26) and (27) respectively.

$$
G_{1}(s)=\frac{\left(1.485 * 10^{8} s^{5}+4.186 * 10^{8} s^{4}+1.436 * 10^{8} s^{3}+4.334 * 10^{6} s^{2}+4.482 * 10^{4} s+153.2\right) e^{-2 s}}{5.533 * 10^{9} s^{6}+2.551 * 10^{9} s^{5}+2.6 * 10^{8} s^{4}+8.53 * 10^{6} s^{3}+1.248 * 10^{5} s^{2}+849.1 s+2.194}
$$




$$
\begin{gathered}
G_{2}(s)=\frac{\left(1.485 * 10^{8} s^{5}+4.186 * 10^{8} s^{4}+1.436 * 10^{8} s^{3}+4.334 * 10^{6} s^{2}+4.482 * 10^{4} s+1\right.}{1.129 * 10^{12} s^{6}+4.407 * 10^{11} s^{5}+2.297 * 10^{10} s^{4}+5.055 * 10^{8} s^{3}+5.616 * 10^{6} s^{2}+3.11} \\
C_{Z N}=\frac{0.0053352(1+26 s)}{s} \\
C_{I M C}=\frac{-1.9865 * 10^{12}(1+83 s)(1+12 s)(1+3.6 s)\left(1+0.98 s+(0.54 s)^{2}\right)}{(1+0.39 s)\left(1-2.6 * 10^{15} s\right)(1+3.4 s)\left(1+0.88 s+(0.52 s)^{2}\right)} \\
C_{L Q G}=\frac{-1.9962 * 10^{12}(1-0.00011 s)(1+0.5 s)(1+4.8 s)(1+12 s)(1+83 s)}{(1+0.47 s)\left(1-9.3 * 10^{14} s\right)(1+4.5 s)\left(1+1.7 s+(1.5 s)^{2}\right)}
\end{gathered}
$$

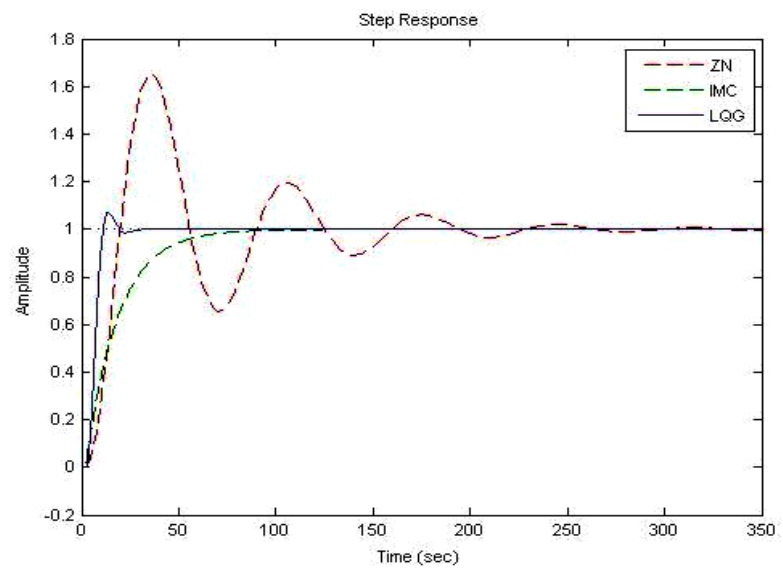

Figure 7. Set point tracking responses of $\mathrm{ZN}$, IMC and LQG controllers for SISO1

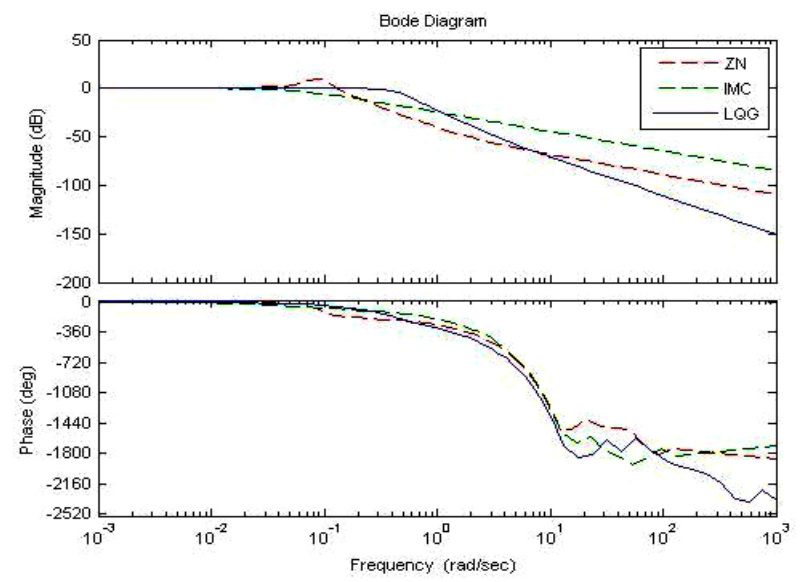

Figure 8. Bode plots for ZN, IMC and LQG controllers for SISO1

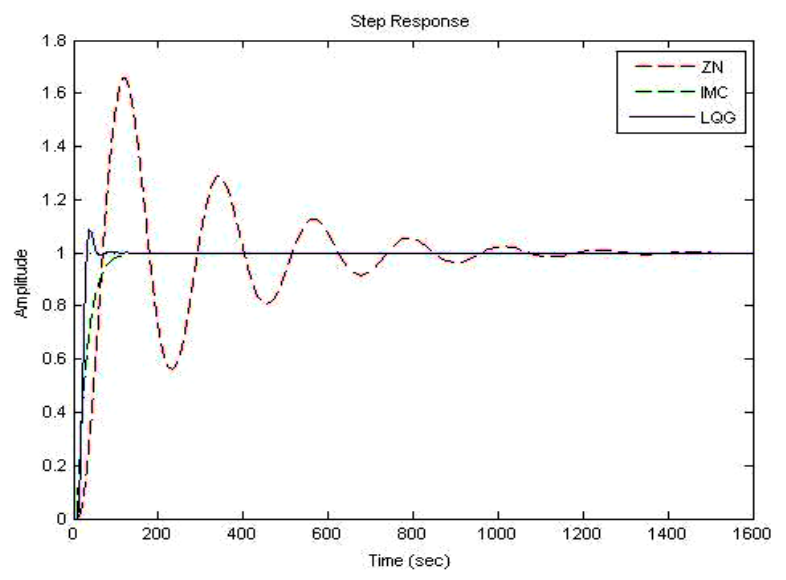

Figure 9. Set point tracking responses of $\mathrm{ZN}$, IMC and LQG controllers for SISO2

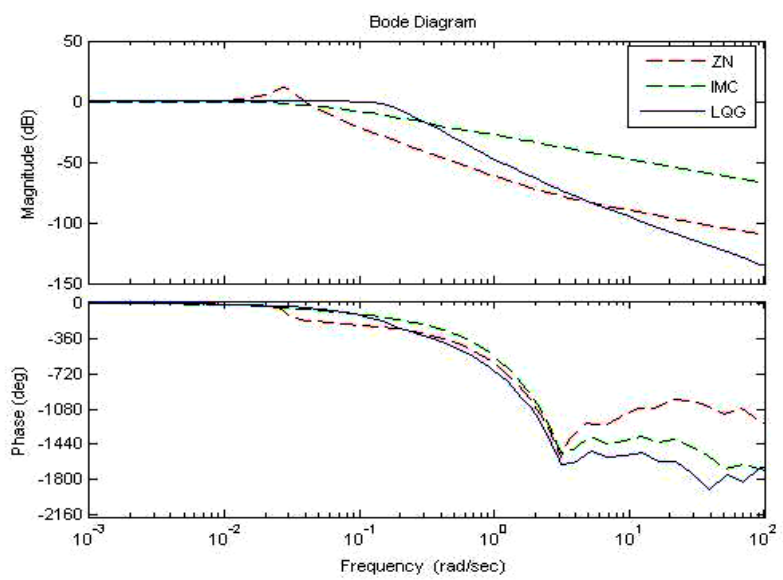

Figure 10. Bode plots for ZN, IMC and LQG controllers for $\mathrm{SISO} 2$

$$
\begin{gathered}
C_{Z N}=\frac{0.026193(1+91 s)}{s} \\
C_{I M C}=\frac{8.2346 * 10^{15}(1+3.5 s)(1+85 s)(1+75 s)\left(1+4 s+(2.3 s)^{2}\right)}{(1+0.41 s)\left(1+5.8 * 10^{17} s\right)(1+3.3 s)\left(1+3 s+(2 s)^{2}\right)} \\
C_{L Q G}=\frac{6.7426 * 10^{14}(1+0.0004 s)(1+75 s)(1+85 s)\left(1+3.9 s+(2.2 s)^{2}\right)}{\left(1+3 * 10^{16} s\right)\left(1+3.3 s+(1.8 s)^{2}\right)\left(1+3 s+(4.1 s)^{2}\right)}
\end{gathered}
$$


Table II. Performance parameters of ZN, IMC and LQG controllers for SISO1

\begin{tabular}{|c|c|c|c|c|}
\hline 导 & 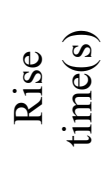 & 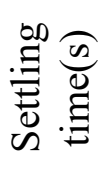 & $\frac{\substack{\frac{1}{0} \\
0}}{e^{2}}$ & 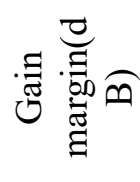 \\
\hline $\mathrm{ZN}$ & 12 & 218 & 65.3 & 7.24 \\
\hline IMC & 37.2 & 68.2 & 0 & 22.8 \\
\hline LQG & 5.74 & 18 & 7.05 & 4.12 \\
\hline
\end{tabular}

Table III. Performance parameters of ZN, IMC and LQG controllers for SISO 2

\begin{tabular}{|c|c|c|c|c|}
\hline 导 & $\underset{\mathscr{E}}{\stackrel{\Xi}{\Xi}}$ & 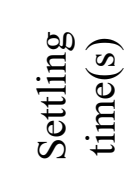 & $\begin{array}{l}\frac{0}{\sqrt[n]{0}} \\
\stackrel{0}{0} \\
e^{2}\end{array}$ & 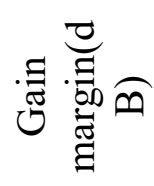 \\
\hline $\mathrm{ZN}$ & 40 & 1030 & 65.5 & 1.8 \\
\hline IMC & 52 & 99.3 & 0 & 14.5 \\
\hline LQG & 14.5 & 50.9 & 8.67 & 1.88 \\
\hline
\end{tabular}

The above IMC controller has been designed with dominant closed loop time constant $=16.9816$.

The set point tracking responses of these controllers are depicted in figure 7 and the corresponding Bode plots are shown in figure 8. The corresponding performance parameters are specified in table II.

The above IMC controller has been designed with dominant closed loop time constant $=23.87$.

The set point tracking responses of these controllers are depicted in figure 9 and the corresponding Bode plots are shown in figure 10. The corresponding performance parameters are specified in table III.

\section{CONCLUSION}

In the present paper a $2 \times 2$ MIMO boiler turbine process is taken up. Having done its decoupling to split it into two separate SISO systems, controllers are designed for both using ZN, IMC and LQG techniques and their performance is compared. It has been found that performance of IMC controller is much better than that of $\mathrm{ZN}$ controller in terms of both, transient and steady state responses. But, the LQG controller comes up with the best performance amongst all with least settling time and smallest peak overshoot.

\section{REFERENCES}

[1] M.Sarailoo, B. Rezaie and Z. Rahmani, "MLD Model of Boiler Turbine System based on PWA Linearization approach," International Journal of Computer Science and Engineering, 2(4), 2012, pp. 88-92.

[2] Zhang Hua Guang and Lilong Cai, "Multivariable Fuzzy Generalized Predictive Control," Cybernetics and Systems :An International Journal, Taylor \& Francis, 2002, pp 33:69-99.

[3] S. K. Sunori, P. K. Juneja, M. Chaturvedi, P. Aswal, S. K. Singh, S. Shree, "GA based optimization of quality of sugar in sugar industry," Ciencia e Tecnica Vitivinicola journal, Vol. 31 No 4, 2016.

[4] Sandeep Kumar Sunori, Pradeep Kumar Juneja and Anamika Bhatia Jain, "Model Predictive Control System Design for Boiler Turbine Process," IJECE, 2015, pp.10541061.

[5] Sandeep Kumar Sunori and Pradeep Kumar Juneja, "Controller Design for MIMO Boiler Turbine Process," IJCTA, 2015, pp.477-486.

[6] Husain Ahmed and Abha Rajoriya, "Performance Assessment of Tuning Methods for PID Controller Parameter used for Position Control of DC motor," International Journal of $\mathrm{u}$ and e Service, Science and Technology, 2014, pp.139-150.

[7] Ramneet Singh, Rajni Bala , Bhavi Bhatia, "Internal Model Control(IMC) and IMC based PID Controller," International Journal of Advanced Research in Computer Science and Software Engineering, 2014, pp.915922.

[8] Ian G. Horn, Jeffery R. Arulandu, Christopher J. Gombas, Jeremy G. VanAntwerp, Richard D. Braatz, "Improved Filter Design in Internal Model Control," Ind. Eng. Chem. Res. 1996,35, pp.3437-3441.

[9] Scali, C., Semino, D., Morari M., "Comparison of Internal Model Control and 
Linear Quadratic Optimal Control for SISO

Systems", Ind. Eng. Chem. Res., 1992.

[10] Danial E.Rivera and Melvin E. Flores, "Internal Model Control", Control Systems, Robotics and Automation-Vol-II.

[11] Ragnar Eide, Per Magne Egelid, Alexander Stamso, Hamid Reza Karimi, "LQG Control Design for Balancing an Inverted Pendulum Mobile Robot", Intelligent Control and Automation", 2011, pp. 160-166. 